\title{
Abdominal sacrocolpopexy with Pelvicol xenograft and concomitant Burch colposuspension
}

\author{
This article was published in the following Dove Press journal: \\ International Journal of Women's Health \\ 6 September 2017 \\ Number of times this article has been viewed
}

\author{
Sameh Hijazi ${ }^{1,2}$ \\ Dieter Echtle ${ }^{3}$ \\ Omar M Aboumarzouk ${ }^{4}$ \\ Elmar Heinrich ${ }^{2,5}$ \\ 'Department of Urology, Klinikum \\ Ibbenbüeren, Ibbenbüeren, \\ ${ }^{2}$ Department of Urology, University \\ Medical Center, Goettingen, \\ ${ }^{3}$ Department of Urology, Städtische \\ Kliniken Mönchengladbach, \\ Mönchengladbach, Germany; ${ }^{4}$ Urology \\ Department, Newport, Wales, UK; \\ ${ }^{5}$ Department of Urology, Klinikum \\ Wels-Grieskirchen, Standort Wels, \\ Austria
}

Purpose: To evaluate the efficacy of Pelvicol xenograft use during abdominal sacrocolpopexy to repair pelvic organ prolapse (POP).

Patients and methods: A total of 27 consecutive women with symptomatic POP were included in this study. A POP-quantification system and International Continence Society classification were used. Functional and anatomical outcomes were assessed. Subjective outcomes and physical activity after surgery were evaluated due to modified quality of life questionnaire.

Results: Median follow-up was 21 months (range: 16 to 41 months). Twenty-four (89\%) patients were available for anatomical and subjective evaluation. Preoperative POP- quantification classification was: stage I: $11.1 \%$, stage II: $25.9 \%$, stage III: $48.2 \%$, and stage IV: $14.8 \%$. Overall, pad usage significantly decreased (mean 4.8 vs 1 pads, $P=0.001$ ). Stress urinary incontinence significantly improved after surgery in nine women $(P=0.001)$. An additional five women were completely continent. No de-novo incontinence developed. Six women with preoperative urinary retention improved in the amount of residual urine postoperative (mean $35 \mathrm{vs} 165 \mathrm{~mL}$ ). Failure rate was $8.3 \%$ at 3 and 11 months after surgery, requiring a second reconstruction. There was no graft related complications or graft rejections necessitating removal occurring. Response rate of the questionnaire was $67 \%$. Two women reported no interference in physical activity after 2 postoperative months, five women after 5 months, and five women 1 year later. Pelvic pain (vaginal pain) was partly improved in eight patients, postoperatively, and ten patients had complete resolution of pain after surgery.

Conclusion: This study demonstrates that abdominal sacrocolpopexy is an effective surgical treatment in correcting POP. The use of Pelvicol is associated with a high recurrence rate and increased failure rate compared to traditional sacrocolpopexy with mesh. Larger clinical trials to evaluate the functional and anatomical outcomes are needed.

Keywords: prolapse, sacrocolpopexy, implant, xenograft, Pelvicol

\section{Introduction}

Pelvic organ prolapse (POP) is highly prevalent in women $(30 \%-50 \%)$, with a $11 \%$ lifetime risk of requiring surgical repair. ${ }^{1-4}$ The cause of prolapse is unknown, however risk factors include age, increasing number of gravidity and vaginal deliveries, obesity, chronic cough, constipation, and a history of hysterectomy. ${ }^{1,3}$ Urinary and fecal incontinence, vaginal ulceration, problems with defecation, and sexual dysfunction are the most troublesome symptoms. ${ }^{1}$

Sacrocolpopexy is the gold standard procedure for POP with excellent anatomical and functional outcomes. ${ }^{4}$ It can be performed abdominally, laparoscopically or robotically. ${ }^{5,6}$ There are a number of advantages to a patient with laparoscopic sacrocolpopexy versus open procedure. Pain is reduced due to smaller incisions and recovery times are shorter. ${ }^{5,6}$ The use of an implant to substitute the deficient level support
Correspondence: Sameh Hijazi Department of Urology, Klinikum

Ibbenbüeren, Germany

Tel +49545I52 205I

Fax +49545152 2150

Email sameh_hijasi@yahoo.de
International Journal of Women's Health 2017:9 625-630

(c) (1) (8) ๑ 2017 Hijazi et al. This work is published and licensed by Dove Medical Press Limited. The full terms of this license are available at https:/www.dovepress.com/terms.php cc. hereby accept the Terms. Non-commercial uses of the work are permitted without any further permission from Dove Medical Press Limited, provided the work is properly attributed. For permision for commercial use of this work, please see paragraphs 4.2 and 5 of our Terms (https://www.dovepress.com/terms.php). 
significantly improves the long-term anatomical results. ${ }^{5}$ Macroporous polypropylene grafts are more commonly used, however are associated with complications such as erosion and pain, which can render the patient in a worse state of health. ${ }^{5,7}$ To reduce the complication rates, implant of native tissue grafts has been gaining popularity. Bioderived matrices have been used and are highly tolerated as they induce a mild inflammatory response, however, little scientific data supporting the use of xenografts is available. ${ }^{7}$

With this in mind, we aimed to evaluate the safety and efficacy of the xenograft Pelvicol abdominal sacrocolpopexy (ASC) and concomitant colposuspension.

\section{Patients and methods}

We performed a single center study including 27 patients undergoing ASC treatment for POP between March 2011 and March 2013. All patients underwent preoperative urodynamic studies as a standard practice. Prolapse evaluation was conducted using a posterior Sims speculum placed in the anterior vaginal fornix. ${ }^{8}$ Diagnosis of stress urinary incontinence (SUI), mixed incontinence, detrusor over activity, voiding dysfunction and residual urinary were documented.

Data was prospectively collated and included patient demographics (age, body mass index, parity, American Society of Anesthesiologists score [I-IV], the classification of POP according with the International Continence Society and POP-quantification [POP-Q] system criteria, and a comparison of the pre and post-operative symptoms based on pad usage, voiding frequency, nocturia, residual urine, and dysuria). ${ }^{8}$ Prolapse reduction was performed for women with advanced POP (stage II-IV). At least 1 year after surgery, women who underwent ASC were asked to complete a validated standardized prolapse quality of life questionnaire. ${ }^{9}$ The Clavien-modified grading system was used to classify any complications. The study was approved by the local ethics committee of the University Medical Center Goettingen (approval 5/4/15). All patients provided written informed consent for this study. Two experienced surgeons with over 10 years of female urological experience at a tertiary referral center performed all procedures. During ASC, we substituted the porcine graft (Pelvicol ${ }^{\circledR} 2 \times 4 \mathrm{~cm}$, Bard, UK) in all patients. Women diagnosed with a prolapse reduction, either with or without SUI, underwent incontinence surgery by Burch procedure at the time of ASC. All patients were permanently catheterized for 5 days postoperatively. A prophylactically antibiotic with cefuroxime $1.5 \mathrm{~g}$ intravenously as a single shot was given to all women perioperatively.
Patients were followed-up routinely at 3, 6 and 12 months. Women in these practices were asked at each postoperative visit about lower urinary tract symptoms, SUI, frequency and urgency including anatomical evaluation and subjective outcomes evaluation. Postoperative anatomic failure was defined as POP-Q > II.

\section{Operative technique}

The procedure began with bladder catheterize and insertion of vaginal dressing forceps with a fixed swab into the vagina. Procedures were performed at the Pfannenstiel incision and transperitoneal in all patients. Alternatively, a median laparotomy was occasionally used. The vaginal stump was exposed and the peritoneum was opened up to reveal in case of any previous hysterectomy. If a previous hysterectomy was indicated a supracervical hysterectomy was performed and the xenograft was fixed onto the cervical stump, in any case of uterus preservation the fixation was performed onto the posterior cervical wall. After exposure and palpation of the promontorium, the peritoneum was opened above the promontorium and the presacral fat tissue was loosened and removed from the os sacrum (height S3-S4). This allowed for the surface of the anterior longitudinal ligament to become visible. A $4 \mathrm{~cm}$ long, and $2 \mathrm{~cm}$ wide Pelvicol implant was then inserted into the abdomen and positioned longitudinally between the promontorium and the vaginal stump. The xenograft was fixed onto the vaginal stump through three single sutures (Ethibond 0; Ethicon, Somerville, NJ, USA). While pushing up the vaginal stump with the swab intravaginal, however, care was taken to ensure that the needle did not grasp the swab and stitch it to the surface. Three simple interrupted stiches were then stitched into the longitudinal ligament and the proximal end of the xenograft was attached to the longitudinal ligament. Peritonealization of the vaginal stump was then undertaken. Peritoneal closure above the xenograft was then performed through continuous suture (Vicryl 3.0; Ethicon) (Figure 1). ASC was followed by Burch colposuspension as a standard technique.

\section{Statistical analysis}

Data was analyzed using the Statistical Package for the Social Sciences, version 17 (IBM Corp., Armonk, NY, USA) program. We used a two-sample $t$-test for continuous data and Chi square test for dichotomous data. The significance level was set at a $P$-value of $<0.05$.

\section{Results}

A total of 27 patients were included. Patient demographic are shown in Table 1. The median follow-up was 21 months 

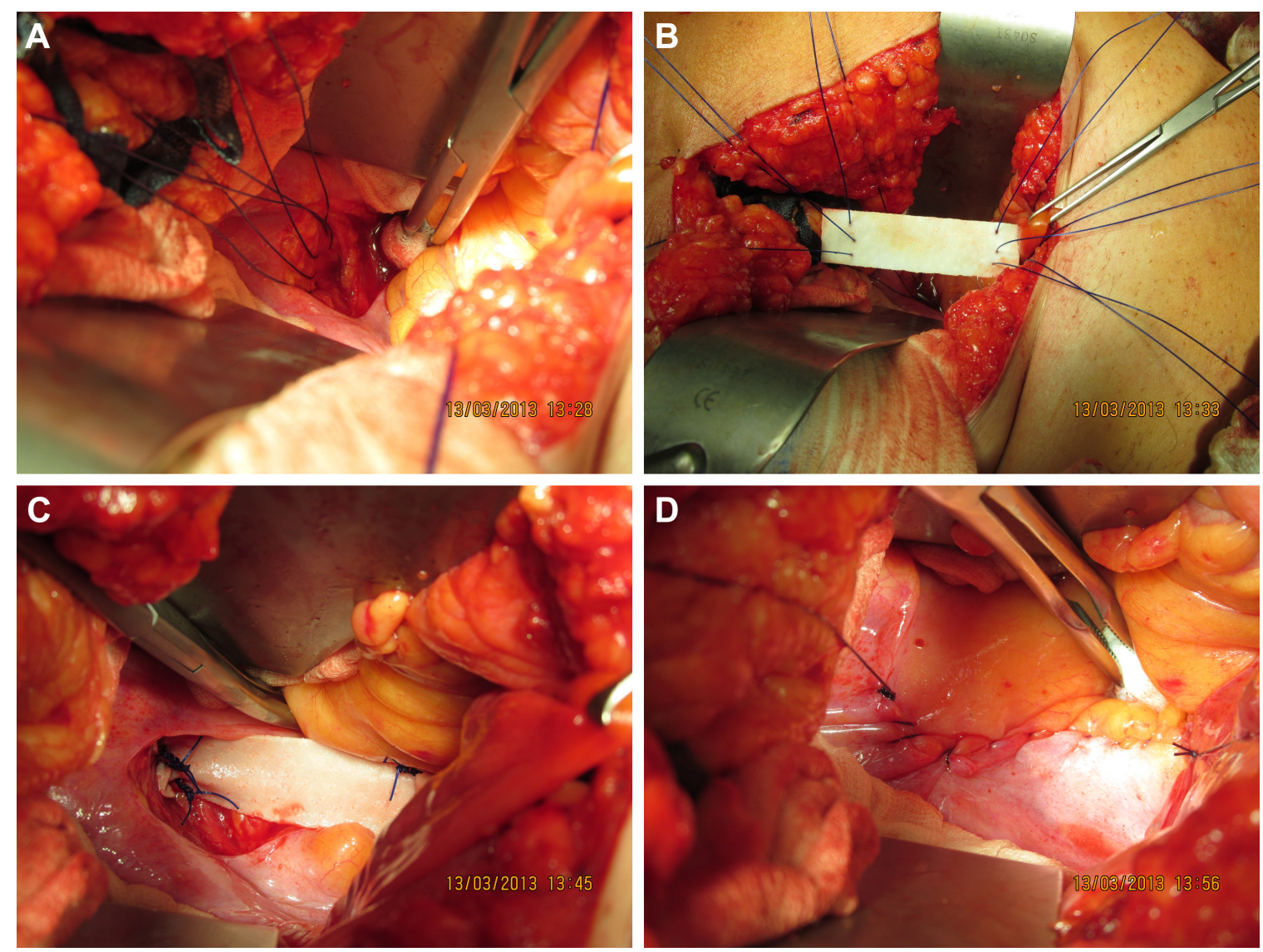

Figure I Abdominal sacrocolpopexy.

Notes: (A) Three single suture (Etibond; Ethicon, Somerville, NJ, USA) submitted in Lig. longitudinal ligament. (B and C) Pelvicol implant fixed between promontorium and vaginal stump. (D) Peritoneal closure above the Pelvicol through continuous suture (Vicryl; Ethicon).

(range: 16 to 41 months). Baseline and end of study symptom comparisons are displayed in Table 2.

SUI had significantly improved after surgery in 14 women $(P=0.001)$. The use of continence pads significantly decreased postoperatively (mean 1 vs 4.8 pads, $P=0.001$ ). None of the preoperatively continent patients developed de novo incontinence. All women with preoperative urinary retention emptied their bladder without significant urine residual postoperatively.

Two patients had a prolapse recurrence (failure rate $8.3 \%$ ) after ASC (one patient POP-Q I and one patient POP-Q II). The time to anatomical failure was 3 and 11 months after surgery. Both underwent secondary operations with ASC with xenograft. Additional procedures and perioperative complications are shown in Table 3.

There were no graft related complications (GRC). There were no graft rejections necessitating removal. A simple urinary tract infection occurred in two women, both treated successfully with antibiotics. Two other women developed complications, one a wound infection which healed successfully and another with an incision hernia.
A total of 18 patients $(67 \%)$ responded to the postoperative questionnaire. Of the women who reported that prolapse interfered substantially with their ability to physical activity, two women reported no interference and ten women described no intrusion. Pelvic pain (vaginal pain) improved in eight patients (44\%) postoperatively, and ten patients (56\%) had complete resolution of pain. Those patients who suffered voiding difficulties $(n=6)$, four had complete resolution (67\%). The majority of the patients (94\%) were satisfied with the outcome while only one woman was not satisfied, with $83 \%$ of patients saying that they would recommend the procedure.

\section{Discussion}

Abdominal sacrocolpopexy is highly effective at anatomically correcting POP involving the vaginal apex..$^{10,11}$ The goal of this study was to evaluate the functional and anatomical outcomes after ASC with xenograft Pelvicol and concomitant colposuspension. The prolapse failure rate in our study was $7.4 \%$. Current studies on sacrocolpopexy using xenograft have demonstrated a higher failure rate. Quiroz et al showed 
Table I Preoperative characteristics of patients

\begin{tabular}{|c|c|}
\hline & Study group $(n=27)$ \\
\hline Age (year, mean $\pm S D)$ & $69 \pm 10$ \\
\hline Body mass index $\left(\mathrm{kg} / \mathrm{m}^{2}\right.$, mean $\left.\pm \mathrm{SD}\right)$ & $25.6 \pm 3.2$ \\
\hline Parity $(n \pm S D)$ & $3 \pm 2$ \\
\hline \multicolumn{2}{|l|}{ ASA (n [\%]) } \\
\hline ASA I & $13(48.2)$ \\
\hline ASA II & $8(29.6)$ \\
\hline ASA III & $5(18.5)$ \\
\hline ASA IV & I (3.7) \\
\hline \multicolumn{2}{|l|}{ Prolapse stage (n [\%]) } \\
\hline POP-Q I & $3(11.1)$ \\
\hline POP-Q II & $7(25.9)$ \\
\hline POP-Q III & $13(48.2)$ \\
\hline POP-Q IV & $4(14.8)$ \\
\hline \multicolumn{2}{|l|}{ Additional descensus (n [\%]) } \\
\hline Anterior compartment & 7 (27.9) \\
\hline Posterior compartment & $4(14.8)$ \\
\hline \multicolumn{2}{|l|}{ Symptoms (n [\%]) } \\
\hline Stress incontinence & $14(5 \mid .9)$ \\
\hline Urge incontinence & $3(11.1)$ \\
\hline Mixed incontinence & $4(14.8)$ \\
\hline Voiding dysfunction/residual urinary & $6(22.2)$ \\
\hline Dyspareunia & $8(29.6)$ \\
\hline Vaginal pain & $12(44.4)$ \\
\hline \multicolumn{2}{|c|}{ History of urogynecological operations (n [\%]) } \\
\hline Hysterectomy & II (40.7) \\
\hline TVT (tension free tape) & $3(11.4)$ \\
\hline Burch & $2(7.4)$ \\
\hline
\end{tabular}

Abbreviations: ASA, american society of anaesthesiologists; POP-Q, pelvic organ prolapse quantification; SD, standard deviation.

that Pelvicol had a significantly higher anatomical relapse rate in ASC compared to synthetic implants $(11 \%$ vs $7 \%) .{ }^{12}$ A recent randomized controlled trial showed a $7 \%$ failure rate in the Pelvicol group. ${ }^{13}$ Deprest et al described a similarly significant higher prolapse recurrence rate at vault prolapse in women who underwent sacrocolpopexy with Pelvicol compared to synthetic mesh (21\% vs 3\%). ${ }^{14}$ However, they did not find any significant difference in functional outcome.

The initial drive to using xenograft was based on early experimental reports. These data demonstrated that xenograft induce a smaller and moderately anti-inflammatory reaction and a lower risk to local complications. ${ }^{15,16}$ Our experience

Table 2 Urinary symptoms preoperative and at follow-up

\begin{tabular}{llll}
\hline & $\begin{array}{l}\text { Preoperative } \\
\text { (n [\%]) }\end{array}$ & $\begin{array}{l}\text { Follow-up } \\
\text { (n [\%]) }\end{array}$ & P-value \\
\hline Pads (mean \pm SD, range) & $4.8 \pm 2.6(3-10)$ & $\mathrm{I} \pm \mathrm{I} .9(0-5)$ & $0.00 \mathrm{I}$ \\
$\begin{array}{l}\text { Voiding frequency } \\
\text { (mean } \pm \text { SD, range) }\end{array}$ & $8 \pm 2.8(4-13)$ & $4 \pm \mathrm{I}(3-6)$ & $0.000 \mathrm{I}$ \\
$\begin{array}{l}\text { Residual urinary (mean, } \mathrm{mL}) \\
\text { Dysuria }\end{array}$ & $\mathrm{I} 65$ & 35 & $0.000 \mathrm{I}$ \\
Nocturia (mean $\pm \mathrm{SD}$, range) & $\mathrm{I} 4 \pm 2(3-9)$ & 5 & 0.002 \\
\hline
\end{tabular}

Table 3 Additional procedure and perioperative complications and anatomical failure

\begin{tabular}{ll}
\hline & $\mathbf{n ~ ( \% )}$ \\
\hline Additional procedure & \\
Hysterectomy & $3(\mathrm{II})$ \\
Uterus myomas excision & $\mathrm{I}(3.7)$ \\
Adhesiolyse & $7(26)$ \\
Insertion of suprapubic catheter & $\mathrm{I}(5(56)$ \\
Ovarian cyst extirpation & $\mathrm{I}(3.7)$ \\
Adenectomy & $\mathrm{I}(3.7)$ \\
Perioperative complications & \\
Urinary tract infection & $2(7.4)$ \\
Wound healing deficit & $\mathrm{I}(3.7)$ \\
Incisional hernia & $\mathrm{I}(3.7)$ \\
Anatomical failure & $2(7.4)$ \\
\hline
\end{tabular}

confirmed this hypothesis. In our study, we did not notice any GRC. This may be due to a shorter follow-up period. Deprest et al reported no significant differences in the GRC rate between Pelvicol and the control group in a median follow-up of 34 months (12\% to $11 \%)$. ${ }^{14}$ Quiroz et al observed an even higher GRC rate with Pelvicol compared with synthetics. ${ }^{12}$ We peritonealized the xenograft to reduce the infection rate and avoid contact with the intestine.

The incidence of POP with concomitant SUI is not well established and is reported as ranging from $15 \%$ to $80 \% .^{17,18}$ The replacement of a prolapse into the intended postoperative position could be more at risk for postoperative SUI in currently continent women because of the change in the vaginal axis. Thus, in the continent patient with POP, the surgeon is left with one of three options: reserving a second incontinence operation for women whose SUI symptoms warrant it; a prophylactic anti-incontinence procedure with the risk of overtreatment, or a postoperative wait and watch approach. Several studies have indicated various incontinence rates after different concomitant prophylactic anti-incontinence operations. ${ }^{19,20}$ The Colpopexy and Urinary Reduction Efforts study described significantly higher postoperative SUI rates in women after ASC compared with women after ASC and prophylactic anti-incontinence procedure (Burch operation) in a 2-year follow-up ( $41 \%$ vs $26 \%$ ). ${ }^{21}$ Contrarily, Constantini et al reported a significantly higher postoperative incontinence rate in women who underwent ASC and concomitant Burch compared with women after ASC without prophylactic anti-incontinence operation in a 8 -year follow-up (29\% vs $16 \%){ }^{22}$ The discrepancies with outcomes in both trials are probably due to the sacropexy technique, patient enrolment and length of follow-up. Cosson et al reported that only $34 \%$ of women with prolapse and preoperative urinary incontinence achieved a complete postoperative continence. ${ }^{23}$ 
Our results confirm Brubaker et al's observations. ${ }^{21}$ Frequency of postoperative incontinence after ASC and Burch was low. The odds of suffering SUI after ASC were not great in patients who had concomitant Burch colposuspension. In our study, multivariate analyses showed that concomitant colposuspension decreased the risk of postoperative SUI without increasing the perioperative morbidity, voiding dysfunction and urinary retention. In our opinion, all patients must be counselled preoperative about the opportunity of a prophylactic anti-incontinence procedure and their advantages and disadvantages.

\section{Limitations}

There are some limitations to our study. The number of enrolled patients in the study was small $(n=27)$, the follow-up period was short (mean 21 months), and the percentage of patients who responded to the questionnaire was quite low $(68 \%)$. Nonetheless, our study was strengthened by the meticulous use of our protocol, which yielded significant improvements in our patients. However, a randomized controlled trial could shed more light.

\section{Conclusion}

Abdominal sacrocolpopexy is an efficient treatment for genital prolapse with excellent anatomical and functional outcomes and a significant postoperative reduction of all assessed symptoms. The usage of the porcine graft, Pelvicol, is associated with low GRCs and high failure rate. Additional Burch colposuspension during sacrocolpopexy is an effective prophylaxis for postoperative incontinence. In future, larger and prospective, randomized clinical trials and a long-term follow-up are needed to further evaluate durability, anatomical outcomes and patient satisfaction after ASC with xenograft.

\section{Disclosure}

The authors report no conflicts of interest in this work.

\section{References}

1. Hendrix SL, Clark A, Nygaard I, Aragaki A, Barnabei V, McTiernan A. Pelvic organ prolapse in the Women's Health Initiative: gravity and gravidity. Am J Obstet Gynecol. 2002;186(6):1160-1166.

2. Olsen AL, Smith VJ, Bergstrom JO, Colling JC, Clark AL. Epidemiology of surgically managed pelvic organ prolapse and urinary incontinence. Obstet Gynecol. 1997;89(4):501-506.

3. Swift SE. The distribution of pelvic organ support in a population of female subjects seen for routine gynecologic health care. Am J Obstet Gynecol. 2000;183(2):277-285.

4. Maher C, Baessler K, Glazener CM, Adams EJ, Hagen S. Surgical management of pelvic organ prolapse in women. Cochrane Database Syst Rev. 2007;(3):CD004014.

5. Nygaard IE, McCreery R, Brubaker L, et al. Abdominal sacrocolpopexy: a comprehensive review. Obstet Gynecol. 2004;104(4):805-823.
6. Rozet F, Mandron E, Arroyo C, et al. Laparoscopic sacral colpopexy approach for genitourinary prolapse: experience with 363 cases. Eur Urol. 2005;47(2):230-236.

7. Claerhout F, Verbist G, Verbeken E, Konstantinovic M, De Ridder D, Deprest J. Fate of collagen-based implants used in pelvic floor surgery: a 2-year follow-up study in a rabbit model. Am J Obstet Gynecol. 2008; 198(1):94.e1-e6.

8. Bump RC, Mattiasson A, Bø K, et al. The standardization of terminology of female pelvic organ prolapse and pelvic floor dysfunction. Am J Obstet Gynecol. 1996;175(1):10-17.

9. Digesu GA, Khullar V, Cardozo L, Robinson D, Salvatore S. P-QOL: a validated questionnaire to assess the symptoms and quality of life of women with urogenital prolapse. Int Urogynecol J Pelvic Floor Dysfunct. 2005;16(3):176-181.

10. Brubaker L, Cundiff GW, Fine P, et al. Abdominal sacrocolpopexy with Burch colposuspension to reduce urinary stress incontinence. N Engl J Med. 2006;354(15):1557-1566.

11. Diana M, Zoppe C, Mastrangeli B. Treatment of vaginal vault prolapse with abdominal sacral colpopexy using prolene mesh. Am J Surg. 2000; 179(2):126-128.

12. Quiroz LH, Gutman RE, Shippey S, et al. Abdominal sacrocolpopexy: anatomic outcomes with Pelvicol, autologous and synthetic graft materials. Am J Obstet Gynecol. 2008:198(5):557.e1-e5.

13. Hviid U, Hviid TV, Rudnicki M. Porcine skin collagen implants for anterior vaginal wall prolapse: a randomized prospective controlled study. Int Urogynecol J. 2010;21(5):529-534.

14. Deprest J, De Ridder D, Roovers JP, Werbrouck E, Coremans G, Claerhout F. Medium term outcome of laparoscopic sacrocolpopexy with xenografts compared to synthetic grafts. J Urol. 2009;182(5): 2362-2368.

15. Song Z, Peng Z, Liu Z, Yang, J, Tang R, Gu Y. Reconstruction of abdominal wall musculofascial defects with small intestinal submucosa scaffolds seeded with tenocytes in rats. Tissue Eng Part A. 2013;19(13-14):1543-1553. Available from https://www.ncbi.nlm.nih. gov/pmc/articles/PMC3665322/. Accessed February 08, 2017.

16. Konstantinovic ML, Lagae P, Zheng F, Verbeken EK, De Ridder D, Deprest JA. Comparison of host response to polypropylene and noncross-linked porcine small intestine serosal-derived collagen implants in a rat model. BJOG. 2005;112:1554-1560.

17. Fianu S, Kjaeldgaard A, Larson B. Preoperative screening for latent stress urinary incontinence in women with cystocele. Neurourol Urodyn. 1995;4:3.

18. Richardson D, Bent A, Ostergard D. The effect of uterovaginal prolapse on urethrovesical pressure dynamics. Am J Obstet Gynecol. 1983;146: 901-905.

19. Cross CA, Cespedes RD, McGuire EJ. Treatment results using pubovaginal slings in patients with large cystoceles and stress incontinence. J Urol. 1997;158:431-434.

20. Gordon D, Groutz A, Wolman I, Lessing JB, David MP. Development of postoperative urinary stress incontinence in clinically continent patients undergoing prophylactic Kelly plication during genitourinary prolapse repair. Neurourol Urodyn. 1999;18(3):193-198.

21. Brubaker L, Cundiff G, Fine P, et al. A randomized trial of colpopexy and urinary reduction efforts (CARE): design and methods. Control Clin Trials. 2003;24(5):629-642.

22. Costantini E, Lazzeri M, Bini V, Del Zingaro M, Zucchi A, Porena M. Pelvic organ prolapse repair with and without prophylactic concomitant Burch colposuspension in continent women: a randomized, controlled trial with 8-year followup. J Urol. 2010;185(6):2236-2240.

23. Cosson M, Boukerrou M, Narducci F, Occelli B, Querleu D, Crepin G. Long-term results of the Burch procedure combined with abdominal sacrocolpopexy for treatment of vault prolapse. Int Urogynecol $J$. 2003;14(2):104-107. 
International Journal of Women's Health

Dovepress

\section{Publish your work in this journal}

The International Journal of Women's Health is an international, peerreviewed open-access journal publishing original research, reports, editorials, reviews and commentaries on all aspects of women's healthcare including gynecology, obstetrics, and breast cancer. The manuscript management system is completely online and includes Visit http://www.dovepress.com/testimonials.php to read real quotes from published authors.

Submit your manuscript here: http://www.dovepress.com/international-journal-of-womens-health-journal 